\title{
Teaching English Medical Writing in a Blended Setting
}

\author{
http://dx.doi.org/10.3991/ijet.v7i4.2253 \\ Jafar Asgari Arani \\ Kashan University of Medical Sciences, Iran
}

\begin{abstract}
Medical writing activities which may have a context and seem to be engaging may be perceived as demotivating by the students of medicine. This opinion was confirmed by the learners' responses to the open-ended question given to them prior to this study. In their responses students evaluated the writing section of English course negatively. The negative views about the writing course posed a problem to the class teacher. The computer technology and the Internet can easily be integrated into language classroom if activities are designed carefully, and carried out systematically. These attempts brought about a new understanding to teaching and learning: blended learning (BL).
\end{abstract}

The purpose of this research was to investigate students of medicine attitude to blended writing classes. It was conducted with second year learners in the Faculty of Medicine at Kashan University of Medical Sciences. The first reflection aimed at finding out medical students' attitude toward blended writing lessons. Although learners' attitude to writing lessons was negative in the first reflections, they changed into positive in the latter ones. The findings indicated that blended writing class had changed students' perception of writing lessons positively. Therefore, this kind of classes may help students develop a positive attitude towards writing by providing meaningful writing opportunities. Like the student portfolio before it, the weblog faces challenges with practicality and security, but ultimately provides an alternative way to teach and assess authentic writing and reading skills. Blog Assisted Language Learning not only provides teachers with an exciting new way to approach communicative language learning, it also gives the students a new reason to enjoy writing! The paper concludes that Internet tools have the potential to be a transformational technology for teaching and learning writing, and teachers ought to give strong consideration to the setting up their facilities within their learning management system.

Index Terms-Blended Writing Class, Medical Writing, Blog, English Class

\section{INTRODUCTION}

Blended learning approaches combine various online instructional modes with zones for face-to-face interaction. This article proposes that weblogs can be used as a 'middle space' between face-to-face contexts and forms of structured online instructional delivery. The weblog is a malleable and fluid medium through which individuals can develop an individualized voice that can reflect facets of their personal style and idiosyncratic intellectual approaches. This article describes the weblog genre and relates how it can enhance blended learning initiatives especially in contexts in which students are novices in terms of online learning or where the online components of the instructional mix are highly structured or particularly demanding. Constructing weblogs can be of aid in motivating students to write and do research over an extended period of time (as well as share their efforts), giving them a platform from which to analyze the various Internet materials they obtain both independently and in the course of their classroom studies.

Nowadays, Medical English plays an important role in medical education and students are expected to communicate effectively in institutions where English is the medium of instruction.

Students of medicine face the task of mastering content area in subject of medicine which is taught in the target language (English). In such case, teaching and learning of English can help the students to deal successfully with their academic demands and to perform successfully in their disciplines and professional contexts. In the academic context the students are required to produce specific writing genres such as essay, summary, critical review, and research paper. However, focus on the distinguishing regularities of structure of different text types can help learners build a repertoire of the organization and the relevant language forms of different genres. It can also make learners aware of the sociolinguistic role that texts play in particular discourse communities. In postgraduate studies, English plays a vital role in helping to initiate students into the academic community in acquiring not only the language proficiency necessary but the specific genres pertaining to these communities.

It was found that the students attributed their problems in writing to their weak foundation, environment, and methods of teaching English in their countries. Weak foundation is related to the status of English, the students' motivation to learn English, and the teachers' lack of interest. Environmental reasons include the use of the mother tongue, few opportunities to practice English, and isolated culture. On the other hand, methods of teaching English included the medium of instruction, using mother tongue in English classes, writing done partly in the first language, and lack of writing practice in educational institutions.

Writing is perceived and taught by the language teachers as a means of communication. However, the language classrooms in general fail to provide opportunities for using writing to communicate meaning to genuine audience for a specific purpose mainly because students know that their texts will be read either by their teachers or peers even if the instruction includes a specific audience and purpose. Therefore, writing activities which may have a 
context and seem to be engaging may be perceived as demotivating by the students. This opinion was confirmed by the learners' responses to the open-ended question given to them prior to this study. In their responses students evaluated the writing course negatively. These negative views about the writing course posed a problem to the class teacher.

Students are generally unmotivated, fail to see the relevance of the course and hate writing. Designing tasks in which students would be interacting with their genuine audience for a real purpose on the Internet would be a solution by making English as Foreign Language (EFL)classrooms more authentic, interactive, meaningful, real, and functional. This possibility suggests blending classroom with technology. The computer technology and the Internet can easily be integrated into language classroom if activities are designed carefully, and carried out systematically.

There have been early examples of integrating computer, computer technology, and the Internet to the classroom [8]\&[11]. These attempts brought about a new understanding to teaching and learning: blended learning (BL). In its most plain term, blended teaching is a systematic shuffle of elements and teaching approaches to be followed in one class. In other words, students are exposed to different learning environments [9]. In BL and teaching, the principles of classroom teaching are followed, and the general classroom practices are kept as they are; however, new elements are integrated into the course. These elements function differently depending on the goals and objectives of the program. Blending new elements into the existing course can operate at different dimensions; however, one important consideration to make is to what extent the new elements are perceived useful by its primary users, students.

Although traditionally traditional education and distributed learning environments were largely separate as they have used different media and method combinations and have addressed the needs of different audiences", this has been changing with the progressive convergence of traditional face-to-face and distributed learning environments allowing development of blended learning systems [4]. Blended learning offers the possibility of recapturing the traditional values of higher education while meeting the demands and needs of the twenty-first century" [5].

According to Scagnoli [9] blended Classroom + Online learning can help students learn how to build up new knowledge, combine the use of new and traditional tools to explore, select, and evaluate sources and learn to present, share and collaborate with others in real and virtual spaces.

Garrison and Vaughan, [5 (also stated that higher education must start delivering on its promise of providing learning experiences that engage and address the needs of society in the twenty-first century. Considering the role of ICT in today's world, blending face to face instruction with the Internet would be one way to prepare students to the real world in which all types of web technologies have been used intensively for different purposes (9). Change in the learner profile is another reason for BL. Most of the students coming to our classes are digital native as technology comes to their life at early ages and they are content with their computer literacy skills (3).
There are different views on the reasons of increased interest in BL. For example, according to Scagnoli [10] the need for BL was aroused by unsuccessful implementations of e-learning. According to her, it is almost impossible to exclude human from any teaching-learning process. Another reason is - the increasing awareness that blended learning approaches and designs significantly enhances the learning experience" (5(.It is claimed that - the use of ICT tools such as blogs, wiki pages, and brainstorming can be very motivating for the learners" [9]. In this application students publish their own writing and receive comments from outsiders, potentially leading to discussion and further use of the target language.

\section{RESEARCH PARTICIPANTS AND METHOD}

This research was conducted with 40 intermediate level students at Faculty of Medicine, Kashan University of Medical Sciences in the 2010-2011 Academic Year. These students followed a skills based program in the writing section of Special English course. First of all, the teacher registered for the blogging system and developed the web platform to be used as a part of the writing section. The students were introduced to the Weblog and taught how to access, read and post required comments to the blog outside the classroom. After that, they registered to the page. After familiarizing students with the new practice, the first tasks were posted. For each genre covered in the lesson similar procedure was followed. First the most important features of the target genre were discovered by the students through analysis of model texts and then they practiced producing the target genre with controlled face to face activities. The BL writing class was assessed using a portfolio which contained printouts from a collection of the comments that students had made about their attitudes and reflections on this kind of class. At the end of the term they wrote also a final reflection in the cover letter to evaluate the blended writing lesson. All of these should have been written in English and contain the writing patterns they had been taught during the academic year.

\section{DISCUSSION AND CONCLUSION}

Based on the findings of this study it can be concluded that the changing needs of life bring up new issues. Although the paper and pen are the vital instruments for writing, in the digital era medium of communication is also transformed into digits and bytes. In order to catch up with these rapid changes and to prepare our students to real life, some variations like blog can be inserted into course syllabi or school curricula. Based on the idea of most of the students in this study, this BL has either directly or indirectly contributed positively in the following categories.

- Innovative interactive skills

- Effective and productive writing classroom

- Enhanced active learning

- Meaningful situational interaction

- Relaxed student's writing

- Increased self-direct learning

- Less stressful practice

- More chance to revisit lectures 
PAPER

Teaching English Medical Writing IN A Blended Setting

The Blended writing classroom was implemented as a solution to a pedagogical problem the teacher had to cope with. As Zhao [11]stated technology should be implemented to solve pedagogical issues. The issue the teacher had was lack of real audience for writing. However, with the implementation of Blog this problem was solved as the online tasks addressed a need in the virtual world and this need was met by student generated texts. Therefore, the task had a real life goal and authentic audience.

Students who participated in this action research described the blog application as involving, interactional, from real life, reflective, technologic, useful, productive, creative, and innovative. These findings are similar with the findings of Leone's study[7]as the innovation had a great impact on - the learners' language skills, especially in listening and speaking, management of ICT tools, satisfaction levels with the contents proposed, as well as on cross-curriculum objectives such as developing autonomy, building learner confidence, creating networks, promoting collaboration....".

Also learners' description of Blog matches with Jonassen's [6] description of an effective learning environment as according to him an effective learning environment should reflect these features. This suggests that innovation was successful in creating an effective learning environment. Moreover, Jonassen [6] adds that such environments lead to meaningful learning and broader world of experience. This also matches with the findings of the present study. After the intervention, even though students did not explicitly state that the writing class was more meaningful, they also did not view it meaningless as they did before the blended writing course. They also continuously stated that the activities were different and innovative which may lead to a broader world of experience. Furthermore, the web platform provided an interaction opportunity with no place and time boundaries [1]. and learners appreciated this as participants pointed out interaction opportunities provided by the blog in the instant reflections.

Besides these opportunities, students were able to address world wide audience and research for the information they may need [2] as they indicated in their reflections. This type of realistic environment may also nurture the motivation and the findings of this study suggests that students negative views turned into positive ones after the blended writing course was carried out.

Student participation in this practice was voluntary and student drop out was not observed although the frequency of logging in changed from student to student. In her study, Stracke [10] identified three reasons for student drop out. To begin with, - lack of support and connection/complementary between face to face and computer assisted components of the blend" [7] was the first reason. When the BL implemented $\overline{\bar{i}}$ this study is analyzed, it can be easily seen that there was continuous support as the students studied in the computer lab for two-hours every week. Also, the face to face and Blog was integrated and there was reference to class work in the Blog tasks. The second reason she identified was not using hardcopy materials and pen and paper; however, in the practice presented in this study, these continued to be an essential component of student work. Another reason for drop out was learners' rejection of the computer as a way for language learning. However, in the current practice, the Blog was used as a platform for exchanging ideas and information, not for language learning.

\section{IMPLICATIONS}

The findings imply that the approach would result in improvement of students' micro-skills for and motivation in writing, mainly through peer coaching, is highly adaptable either by the teachers (i.e., differentiated instruction through customization of the writing process) or the students themselves (i.e., autonomous learning - choice of how to make use of the group generated resources for their own writing) to suit the writing proficiency levels of individual student groups, and would turn the students' individual differences in the proficiency levels of various micro-skills from a perceived instructional challenge to an advantage in motivating effective peer coaching.

Although this is a small scaled study, students' reflection on the blended writing course has certain implications for teachers and course developers. First of all, teachers must be aware of the fact that when there is an issue in the class, the solution may not be within the class. This can be provided by developing alternative ways of bringing something from real life to the class and taking something from the class to the real world. Especially in the productive skills, the output may need to be addressed to a real audience, which probably leads students to have a real purpose and more interest in doing the task. The other issue that may be of concern is that keeping the class upto-date highly depends on the teacher. With the changes in the technology, needs in the real life might change, so are the tools. In order to keep up with these changes, the teachers need to revisit their roles in the class and improve their skills in technology to make use of platforms which has no place and time boundaries for further classroom activities. The third implication of this study is related with research and computer skills which are generally neglected in writing classes. Before writing, students might be required to do certain amount of research in advance. Moreover, for computer skills, they may also be required to write their written work on the computer rather than with pen and paper. Another issue is students' interest in reflecting on what they do. Therefore, the classroom environment should promote constant reflection opportunities to sort out the problems occurring in the classes or to let some issues which the teacher might have never thought about earlier emerge. The final point is that such web platforms must be encouraged in the other courses in order to form a blog portal of the school. As a conclusion, to let students benefit from the writing practice, both teachers and course book designers need to link the classroom and the real life by designing real life bounded activities, tasks or course books. The outcomes of the blended setting and the use of various active writing strategies were evident in the students' development and mastery of selected skills in medical writing. Additional positive support consisted of the triangulation of students' ongoing input and final evaluations, samples of improved written work, and cumulative course assessments. The use of the blended instructional setting was effective in the medical writing course and warrants further research to ascertain its optimal use. 


\section{PAPER}

\section{TeAching English MedicAl Writing in a Blended Setting}

\section{REFERENCES}

[1] Ahonen, M., Joyce, B., Leino, M. \&Turunen, H. (2003).-Mobile Learning - A Different Viewpointll. In: Kynäslahti, H. \&Seppälä, P. (Eds.) Professional Mobile Learning.Helsinki, IT Pres.

[2] Brooks, D. (2001). W. Web Teaching. A Guide to Designing Interactive Teaching for theWorld Wide Web.Second Edition.Kluwer Academic Publishers, USA.

[3] Dudeney, G. and N. Hockly (2007).How to Teach English with Technology. Malaysia:Pearson Education Limited.

[4] Graham, C. R. (2006) Chapter 1: Blended learning systems: definiton, current trends,future directions. In Bonk, C. J. and Graham, C. R. (eds.), Handbook of BlendedLearning: Global perspectives, local designs (2006). San Francisco, CA: PfeifferPublishing.

[5] Garrison, R. D. \&Vaughan, N. D. (2008). Blended Learning in Higher Education: Framework, Principles, and Guidelines.

[6] Jonassen, D. H. (1992).Cognitive Tools for Learning.Ed by P. A. M. Kommers et al,NATO.

[7] Leone, S. (2008). The use of new technologies in advanced Italian Classes. In I. Olney,G. Lefoe, J. Mantei, \& J. Herrington (Eds.), Proceedings of the Second EmergingTechnologies Conference 2008 (pp.120-129). Wollongong: University of Wollongong.
[8] Salaberry, M. R. (2003). The use of technology for second language learning andteaching: A retrospective. The Modern language Journal, Vol. 85 No. 1 Special Issue: ACentury of Language teaching and research: looking Back and Looking Ahead, Part 2(Spring, 2001), pp. 39-56.

[9] Scagnoli, N. (2005) Blended learning: An instructional challenge and a learningopportunityVoices 186, August/September.

[10] Stracke, E. (2007). A road to understanding: A qualitative study into why learners dropout of a blended language learning (BLL) environment. ReCALL 19 (1), pp. 57-78. http://dx.doi.org/ 10.1017/S0958344007000511

[11] Zhao, Y. (2001). Recent developments in technology and Language learning: Aliterature review and Meta-analysis. CALICO Journal, 21 (1), pp. 7-27.

\section{AUTHOR}

Jafar Asgari Araniis a full time faculty member of Kashan University of Medical Sciences, Iran, English Department. (email: Jafaraskari@yahoo.com)

Received 5 September 2012. Published as resubmitted by the author 3 December 2012. 